OPEN ACCESS

Edited by:

Shevach Friedler,

Barzilai Medical Center, Israel

Reviewed by:

Samer Khoury,

Technion Israel Institute of

Technology, Israel

Yoel Shufaro,

Rabin Medical Center, Israel

*Correspondence:

Jan Tesarik

jtesarik@clinicamargen.com

Specialty section:

This article was submitted to

Assisted Reproduction,

a section of the journal

Frontiers in Reproductive Health

Received: 15 August 2020

Accepted: 02 November 2020

Published: 07 December 2020

Citation:

Tesarik J, Conde-López C, Galán-Lázaro $M$ and Mendoza-Tesarik R (2020) Luteal Phase in Assisted Reproductive Technology.

Front. Reprod. Health 2:595183. doi: 10.3389/frph.2020.595183

\section{Luteal Phase in Assisted Reproductive Technology}

\author{
Jan Tesarik*, Cristina Conde-López, Maribel Galán-Lázaro and Raquel Mendoza-Tesarik \\ MARGen Clinic, Granada, Spain
}

Luteal phase $(\mathrm{LP})$ is the period of time beginning shortly after ovulation and ending either with luteolysis, shortly before menstrual bleeding, or with the establishment of pregnancy. During the LP, the corpus luteum $(C L)$ secretes progesterone and some other hormones that are essential to prepare the uterus for implantation and further development of the embryo, the function known as uterine receptivity. LP deficiency (LPD) can occur when the secretory activity of the $C L$ is deficient, but also in cases of normal CL function, where it is caused by a defective endometrial response to normal levels of progesterone. LPD is particularly frequent in treatments using assisted reproductive technology (ART). Controlled ovarian stimulation usually aims to obtain the highest number possible of good-quality oocytes and requires the use of gonadotropin-releasing hormone $(\mathrm{GnRH})$ analogs, to prevent premature ovulation, as well as an ovulation trigger to achieve timed final oocyte maturation. Altogether, these treatments suppress pituitary secretion of luteinizing hormone $(\mathrm{LH})$, required for the formation and early activity of the $\mathrm{CL}$. In addition to problems of endometrial receptivity for embryos, LPD also leads to dysfunction of the local uterine immune system, with an increased risk of embryo rejection, abnormally high uterine contractility, and restriction of uterine blood flow. There are two alternatives of LPD prevention: a direct administration of exogenous progesterone to restore the physiological progesterone serum concentration independently of the $\mathrm{CL}$ function, on the one hand, and treatments aimed to stimulate the $\mathrm{CL}$ activity so as to increase endogenous progesterone production, on the other hand. In case of pregnancy, some kind of LP support is often needed until the luteal-placental shift occurs. If LPD is caused by defective response of the endometrium and uterine immune cells to normal concentrations of progesterone, a still poorly defined condition, symptomatic treatments are the only available solution currently available.

Keywords: luteal phase, assisted reproduction technology (ART), corpus luteum, progesterone, uterine receptivity, decidualization of endometrium, progesterone-induced blocking factor (PIBF), immune tolerance

\section{INTRODUCTION}

Luteal phase (LP) is the period of time between the transformation of the dominant ovarian follicle into the corpus luteum (CL), shortly after ovulation, and either the establishment of pregnancy or the onset of menstrual bleeding (1). During the LP, the CL secretes progesterone and some other hormones that are vital for maintaining the endometrium in a condition favorable for embryo implantation and its further development (2). The CL secretory activity is maintained by pulsatile secretion of luteinizing hormone (LH) from the pituitary gland (1). However, each CL has 
a programmed life span beyond in which LH support is not sufficient for its maintenance $(3,4)$. Hence, in the absence of pregnancy, LP is terminated by a loss of functional and structural integrity of the CL, referred to as luteolysis (1). If pregnancy is established, the functional life span of the CL is extended by a process termed rescue of the CL (5). This process requires sufficient quantities of human chorionic gonadotropin (HCG) to be secreted by the early implanted embryo (6).

LP deficiency (LPD) refers to a situation where the secretory activity of the CL is impaired, but it can also appear in cases of a normal output of hormones from the CL, where it is caused by a defective endometrial and immune system response (7). Though originally described (8) and recently confirmed $(7,9)$ in natural ovulatory cycles, LPD is particularly frequent in assisted reproductive treatment (ART) attempts using controlled ovarian stimulation protocols $(10,11)$, leading to a need for LP support.

In this review, we will analyze the physiological basis of CL formation and maintenance, the roles of CL secretion for the establishment of pregnancy, the effects of different ovarian stimulation protocols on CL function, and the therapeutic possibilities of substituting for defective CL secretion and restoring the threatened $\mathrm{CL}$ function in the context of ART treatments.

\section{PHYSIOLOGICAL BASIS OF CORPUS LUTEUM FORMATION AND MAINTENANCE}

The formation of the CL is a direct consequence of the pre-ovulatory surge of pituitary $\mathrm{LH}$, which acts through a protein kinase A pathway (2). The LH surge leads to the transformation of granulosa and theca interna cells to granulosalutein and theca-lutein cells, respectively. These steroidogenic cells collaborate with non-steroidogenic (endothelial, immune, and fibroblast) cells, all of which are essential to the synthesis and secretion of steroids (12). Ongoing increased LH levels, following the initial LH surge, are critical to the maintenance of the CL structural and functional integrity (1) until, in the case of pregnancy, this function is taken on by HCG secreted by the early implanted embryo $(6,13)$. This shift, referred to as rescue of the CL $(5,6)$, marks the end of the LP, but the CL will continue to cover the basic needs of the uterus for progesterone until its function is resumed by the placenta, a phenomenon called luteal-placental shift.

\section{ROLE OF CORPUS LUTEUM IN EARLY PREGNANCY}

The principal function of the CL is the secretion of progesterone needed for structural and functional transformations of the endometrium, known as the transition from the proliferative to secretory phase. This phenomenon involves structural and functional changes occurring in epithelial and stromal cells of the endometrium, elongation of terminal arterioles to the endometrial lumen, and a dramatic increase in the number of CD56-/CD16+ uterine natural killer (uNK) cells, which are believed to play a tolerizing role in maternal allorecognition of fetal trophoblasts, rather than cytotoxicity (14). All these changes are orchestrated by a variety of molecules and overall regulated by steroid hormones among which progesterone plays a pivotal role $(15,16)$. In addition to progesterone, different types of cells present in the CL also secrete estradiol, vascular endothelial growth factor (VEGF), endocrine glandderived VEGF (EG-VEGF), and the cytokines interleukin-1 $\beta$ (IL-1 $\beta$ and tumor necrosis factor- $\alpha$ (TNF- $\alpha$ ). All of these minor CL secretory products were shown to be important for proper regulation of the secretion of progesterone, the main CL product (2).

\section{ETIOLOGY OF LUTEAL PHASE DEFICIENCY}

First described by Georgeanna Seagar Jones (17), well before the era of in vitro fertilization (IVF), LPD has later fallen into oblivion until relatively recently. While LPD appears to be more frequent than thought previously even in natural ovulatory cycles (9), it is particularly significant in assisted reproduction. LPD can be caused by two different conditions: first, impaired CL secretory activity and, second, abnormal response of the endometrium to normal concentrations of CL products.

\section{Impaired Corpus Luteum Secretory Activity} In most cases, impaired CL secretory activity is caused by inadequate stimulation by endogenous LH. This condition was already recognized in the early years of IVF (18-20). Initially, impaired CL secretory activity in IVF treatment attempts was attributed to the depletion of granulosa cells, precursors of the future granulosa lutein cells, during follicular aspiration (19), or to supraphysiologic steroid serum concentrations, routinely observed in stimulated cycles, affecting adversely LH secretion needed for CL formation, and maintenance (21). However, later studies pointed to the ovulation triggers, used to promote final oocyte maturation before performing follicular aspiration (Figure 1), or to the supraphysiologic steroid hormones secreted by the multiple CLs in the early LP of an IVF cycle, as the main culprit (22-24).

It has long been known that both estrogens and HCG suppress serum levels of LH, especially when both act together (25). Both actions are associated with conventional ovarian stimulation protocols in which multiple follicle growth leads to supraphysiologic estradiol levels, followed by the injection of HCG as ovulation trigger. In women treated by the long gonadotropin-releasing hormone $(\mathrm{GnRH})$ agonist protocol, where pituitary GnRH release blockage is started in the cycle preceding ovarian stimulation, this deep pituitary suppression may persist after oocyte recovery and contribute further to deficient LH signaling in the forthcoming LP (26). Surprisingly, ovarian stimulation protocols using GnRH antagonists, instead of agonists, to prevent premature LH surge did not improve the situation (23), in spite of the fact that the GnRH antagonists, 


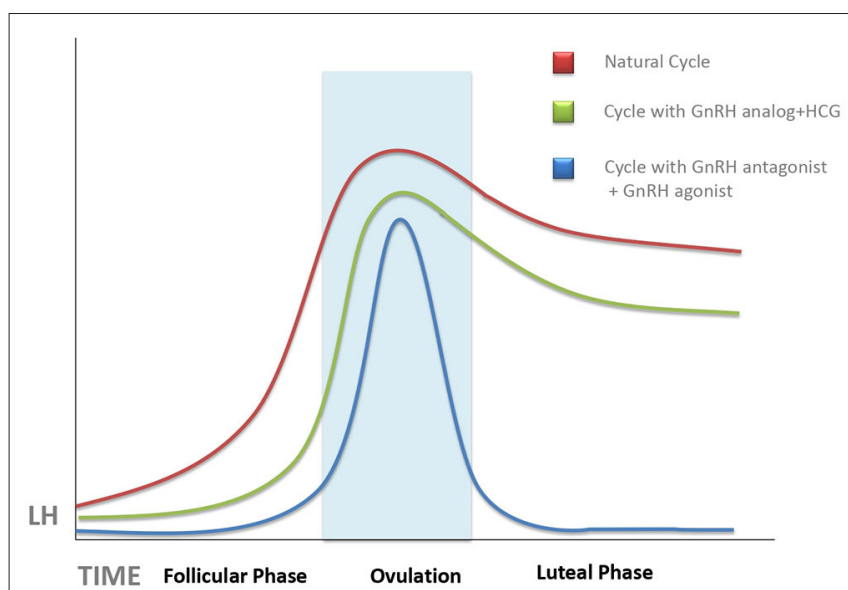

FIGURE 1 | Schematic representation of the evolution of serum luteinizing hormone (LH) concentrations during a natural cycle (red line), after ovarian stimulation cycles triggered with human chorionic gonadotropin (HCG) (green line), and those trigged with gonadotropin-releasing hormone $(\mathrm{GnRH})$ antagonist (blue line). Unless progesterone, $\mathrm{HCG}$, or $\mathrm{GnRH}$ agonist is administered during the luteal phase, there is an abrupt fall of serum $\mathrm{LH}$, which can provoke implantation failure. This tendency is more pronounced in $\mathrm{GnRH}$ agonist-triggered cycles as compared with HCG-triggered ones. unlike the agonists, clear quickly and do not cause a long-term pituitary LH suppression (4).

The degree of LPD was further increased by the use of $\mathrm{GnRH}$ agonists, instead of HCG, as ovulation trigger in $\mathrm{GnRH}$ antagonist-controlled cycles (Figure 1). GnRH agonists have been used as ovulation trigger since the early 1990 s $(27,28)$, but it was later discovered that $\mathrm{GnRH}$ agonist, when used as ovulation trigger, has a more powerful luteolytic effect than HCG (29). This was a limiting factor for the use of $\mathrm{GnRH}$ agonists as ovulation trigger in fresh embryo transfer cycles (except for oocyte donation) until it was discovered, in 2016, that increased luteolysis in $\mathrm{GnRH}$ agonist-triggered cycles can be prevented by continuous GnRH agonist administration throughout the LP, without a need for additional exogenous progesterone supplementation (30) as also confirmed by a recent meta-analysis (31). Dual and double triggers, combining a previous administration of $\mathrm{GnRH}$ agonist, followed by a small dose of HCG, were reported to improve oocyte quality without increasing the risk of severe ovarian hyperstimulation (32). However, the effects of these protocols on the LP remain largely unknown. It is of note that defective LP observed after agonist-triggered ovulation does not occur at random and is more pronounced in some women than in others; therefore, this patient-dependent response may be related to the personal characteristics of each patient's pre-ovulatory physiological surge profile (33).

\section{Abnormal Endometrial Response to Progesterone}

In addition to low progesterone output from the CL, the clinical picture of LPD can also be caused by abnormal endometrial response to normal progesterone levels, a condition known as endometrial progesterone resistance. Most clinical data about progesterone resistance come from analyses of endometrial samples from patients suffering from endometriosis and polycystic ovary syndrome (PCOS).

Endometriosis (34) and PCOS (35) were the first pathological conditions in which progesterone resistance of human endometrium was discovered. In the case of endometriosis, the insensitivity to progesterone was suggested to be caused by chronic inflammation associated with this disease, making part of a vicious cycle whereby inflammation causes progesterone resistance, which further aggravates the inflammatory symptoms (36). As to PCOS, endometrial resistance to progesterone appears to be mainly caused by preferential expression of a less active progesterone receptor isoform in both epithelial and stromal cells of the endometrium (37).

Apart from endometriosis and PCOS, abnormal endometrial response to progesterone is also suspected to occur in some women lacking any of those pathologies, as evidenced by current experience with oocyte donation. In fact, recurrent implantation failure was observed after transfer of excellentquality embryos originated from donated oocytes in spite of apparently normal endometrial proliferative phase and adequate serum progesterone concentrations after embryo transfer (38).

\section{CONSEQUENCES OF LUTEAL PHASE DEFICIENCY}

During the LP, the endometrium undergoes a dynamic transition from proliferative to secretory morphology and function, a process orchestrated directly and indirectly by the sex steroids estrogen and progesterone and mediated by a complex array of secondary autocrine and paracrine factors including cytokines, chemokines, their receptors, and second messengers $(39,40)$. The timing of endometrial receptivity (implantation window) coincides with progesterone-induced downregulation of epithelial estrogen receptor alpha and with a shift in progesterone receptor out of the epithelial cells to the stromal compartment of the endometrium (41). According to some studies, this condition is associated with the appearance of endometrial epithelial pinopodes (42). Pinopodes, also called uterodomes, are smooth, membranous protuberances appearing on the apical surface of uterine epithelium when viewed under the scanning electron microscope. Reduction in the number, or an inappropriate time of maturation, of pinopodes was suggested to be associated with embryo implantation failure, although this conclusion has not yet been confirmed definitively. The role of the pinopodes is still under debate. They have been suggested to mediate pinocytosis and endocytosis of uterine fluid, thus facilitating adhesion of the blastocyst to the endometrium (43), to be directly involved in blastocyst-endometrial interaction through the expression of leukemia inhibitory factor (LIF) (44) or adhesion molecules, such as integrins (45), but all of these mechanisms still remain largely hypothetical (46).

Estrogen and progesterone affect endometrium through both genomic and non-genomic actions using different 
signal transduction pathways, and animal experiments show that selective deficiency of any of the second messengers and downstream signaling pathways can preclude correct endometrial response events in the presence of adequate concentrations of the hormones (47). It is thus conceivable that similar deficiencies can occur spontaneously in women and cause LPD even when estrogen and progesterone production is adequate. Little is known about the prevalence of these abnormalities in humans. Even though they are likely to be less frequent than the CL abnormalities, they have to be taken into consideration for designing the optimal strategy of LPD treatment in each individual patient.

Apart from the disturbance of the molecular signaling underlying endometrium-blastocyst molecular crosstalk required for the blastocyst adhesion and invasion (48), progesterone secretion by the CL also has other biological functions that are essential for implantation and survival of the early implanted embryo. They include the role of progesterone in epithelial and stromal cell remodeling necessary for decidualization (49), moderation of uterine contractility after embryo transfer (50), and feto-maternal immunological crosstalk (51). This latter function of progesterone is mediated by a protein called progesterone-induced blocking factor (PIBF), synthesized by progesterone receptor-expressing lymphocytes and NK cells present both in the peripheral blood and in the decidua. The number of progesterone receptorexpressing lymphocytes increases throughout gestation, and it is significantly lower in women with recurrent miscarriages than in healthy pregnant women of corresponding gestational ages, suggesting a relationship between lymphocyte PR expression and the outcome of pregnancy (52). If PIBF is abnormally low as compared with progesterone, it may indicate relative lymphocytic insensitivity to progesterone (53). This condition creates a potential threat of implantation failure, abortion, and preterm delivery because of dominant Th1-type, pro-inflammatory cytokine production in response to the presence of the embryo, recognized by the immune system as a semiallograft (Figure 2). During normal pregnancy, in progesterone receptor-expressing lymphocytes, which represent $70 \%$ of decidual $\mathrm{T}$ cells (52), progesterone-activated receptor induces local secretion of Th2-type, anti-inflammatory cytokines that mediate the immunological tolerance of the embryo and promote its implantation and survival (52, 53). In particular, $\mathrm{PIBF}$ induces an increase in regulatory $\mathrm{T}$ cells (Tregs) and CD4+ CD25+ T cells whose role is to suppress the immune response (54). In addition to $\mathrm{T}$ cells, progesterone also affects uNK cells, a particular type of NK cells, different from those found in the peripheral blood (54, 55). During pregnancy, these cells lose their cytotoxic functions and play a supportive role by enhancing angiogenesis (43) and by dampening the activity of pro-inflammatory TH17 cells through the secretion of interferon- $\gamma$ (56). They also inhibit the function of cytotoxic $\mathrm{T}$ cells through the expression of immunomodulatory molecules such as galectin-1 and glycodelin A (43).

\section{MANAGEMENT OF LUTEAL PHASE DEFICIENCY IN ASSISTED REPRODUCTIVE TECHNOLOGY}

The etiology of LPD associated with ART treatments has two components: the effect of ART procedures themselves and the individually variable inborn predisposition of each patient. Data show that virtually all women undergoing an ART attempt are prone to $\operatorname{LPD}(57,58)$. It was hypothesized that women who experience LPD in natural cycles are exposed to a more severe LPD after ART treatment than women with normal spontaneous LP $(9,10)$. This relationship, however, still remains to be substantiated.

If the hypothesis of the relationship between LPD in natural and ART cycles was confirmed, it would be important to look for LPD before enrolling patients into an ART protocol. However, there persist serious doubts about whether, and how, LPD can be diagnosed reliably. The criteria used in the original description of LPD were based on the evaluation of basal body temperature charts (detecting a short LP), urine pregnanediol measurement, and a premenstrual endometrial biopsy (16). All of these three criteria have later been challenged (4). Serum progesterone concentration is known to fluctuate, following the rhythm of pituitary LH pulses (58). However, these fluctuations appear to be attenuated in cycles triggered with HCG and, in general, after treatment with ovarian stimulation medications (23). Thus, midluteal serum progesterone concentration still remains to be one of the most employed markers of LPD (59). More recent suggestions are based on uterine transcriptome analysis (46). A customized endometrial receptivity array, containing 238 genes related to endometrial receptivity (59), was suggested to be used in women with recurrent implantation failure (60). However, the utility of this method in the clinical practice has later been questioned (61). More recently, a smaller set of genes has been proposed to assess the receptivity status in biopsies obtained in the secretory phase (61).

\section{Luteal Phase Deficiency With Low Serum Progesterone Levels}

Once LPD with low serum progesterone levels is diagnosed, the optimal treatment strategy has to be established individually in each case. In most cases, LPD can be avoided even without previous diagnosis, by meticulous control of the LP in each ART attempt. There are basically two types of LP support in ART procedures: one using exogenous progesterone preparations via different routes of administration to substitute for progesterone deficiency and the other aiming to stimulate endogenous progesterone production by the CL. The former strategy is feasible in all types of ART procedures, whereas the latter cannot be used in clinical scenarios using artificial LP after previous suppression of ovarian activity, such as most of the treatment attempts using frozen embryo transfer (FET) or donor oocyte cycles.

In the first years of ART history, the usual approach to be used to treat LPD was HCG treatment after embryo transfer 


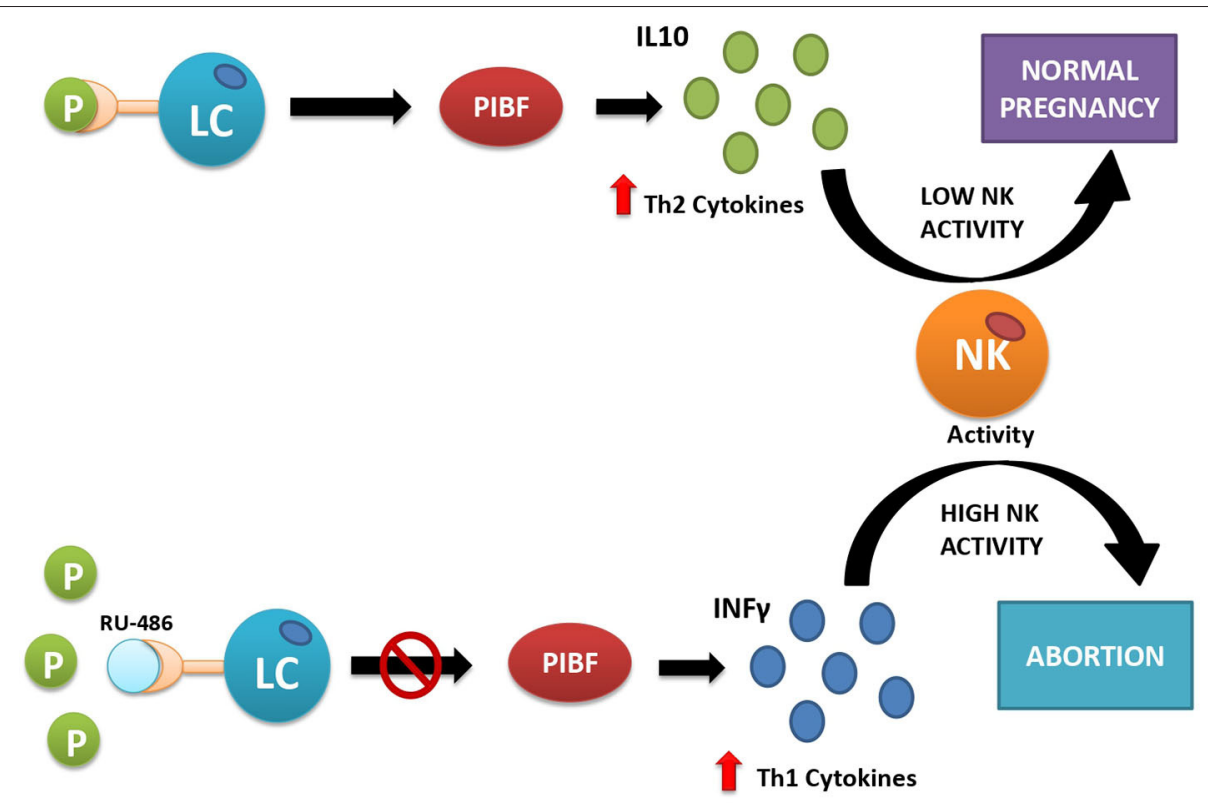

FIGURE 2 | Interactions between progesterone and immune cells under normal conditions (upper part) and after artificially induced progesterone receptor insensitivity with the use of mifepristone (RU-486) (lower part). Under normal conditions (upper part of the figure), progesterone acts as its receptors located on the surface of some lymphocytes (LC). This action provokes the release of Th2-type interleukins (e.g., IL-10), which inhibit cytotoxic action of natural killer (NK) cells and facilitate embryo implantation. If the receptor is inactive, here simulated by blocking the progesterone receptor with the competitive antagonist RU-486 (lower part of the picture), the lymphocytes release Th1-type interleukins, e.g., interferon- $\gamma(\mathrm{IFN}-\gamma)$, which activate cytotoxic action of NK cells against the placental semiallograft, leading to abortion.

(20). However, with the advent of more "aggressive" ovarian stimulation protocols, leading to the recovery of high number of oocytes, it was necessary to use HCG with caution, especially in cases of a high ovarian response, in order to reduce the risk of ovarian hyperstimulation syndrome (62). LP support was thus increasingly performed by a direct substitution of the missing endogenously produced progesterone with exogenous progesterone preparations administered by different routes. Progesterone for LP support can be administered orally, intramuscularly, vaginally, and, most recently, subcutaneously, with each route having different bioavailability and tolerability profiles (63). A recent meta-analysis (31) showed that intramuscularly and vaginally administered progesterone is equally effective, the latter being better supported by the patients. Recently, promising results were obtained with oral administration of dydrogesterone, a synthetic progestin, instead of progesterone for LP support (62). Dydrogesterone is a more patient-friendly treatment because of its oral administration. Moreover, it is not detected by the current laboratory tests for serum progesterone concentration, which makes it possible to detect the occurrence of luteal-placental shift of progesterone production and thus to determine the time from which LP support is no more required $(64,65)$.

More recent studies have revisited the idea of supporting the patient's own progesterone secretion by stimulating the CL activity. Instead of HCG, CL is stimulated by administration of GnRH agonists, which do not increase the risk of ovarian hyperstimulation syndrome, after embryo transfer (53). In addition to stimulating CL function, independently of the ovulation trigger used $(30,55,66,67), \mathrm{GnRH}$ agonists also have a direct beneficial effect on viability of the implanting embryos (68).

\section{Luteal Phase Deficiency With Normal Serum Progesterone Levels}

This form of LPD is quite difficult to diagnose because of the lack of reliable diagnostic tests demonstrating a failure of the endometrium to respond to normal levels of progesterone. Assays based on the analysis of endometrial transcriptome profile (5961) may pave the route, but their interpretation is currently uncertain. Moreover, the transcriptome profile of endometrial cells will not reflect the deficiencies of progesterone-induced synthesis of PIBF by a subset of uterine progesterone receptorexpressing lymphocytes, a condition that can lead to the rejection of the embryo semiallograft (see Consequences of Luteal Phase Deficiency). Consequently, a question arises on how to treat repeated implantation failures and/or miscarriages with normal serum progesterone levels, some of which might be caused by uterine lymphocyte progesterone receptor failure.

Increasing serum progesterone concentration above the physiological levels does not appear to be a solution to this problem because abnormally high serum progesterone concentration can be harmful for endometrial receptivity and decidualization (69). There is currently little information about the prevalence of LPD with normal serum progesterone concentrations. In fact, such cases are likely to go undetected unless specific and not quite usual assays for the detection of the expression of the progesterone receptor and other players 
involved in the progesterone-activated signal transduction pathways are employed. Treatments used in these cases are thus largely symptomatic.

Rejection of the trophoblastic semiallograft by the maternal immune system can be treated by high doses of progesterone, but progesterone alone might not be sufficient. The inflammatory reaction, associated with the secretion of the pro-inflammatory Th1 cytokines, can be mitigated by high doses of melatonin, which also acts as a potent antioxidant agent (70). Due to these effects, melatonin promotes uterine and placental health and, consequently, favors embryo implantation and attenuates the risk of miscarriage (71). Vaginally administered sildenafil was also shown to mitigate maternal rejection of the implanted embryo and fetus (72), presumably by acting at the TNF- $\alpha$ level and modulating Treg and NK cell activity in women with recurrent pregnancy loss (73).

Vitamin D is another molecule that might be of help in women with partial insensitivity of their endometrium to progesterone (74). Indeed, both progesterone and vitamin $\mathrm{D}$ regulate the expression of the homeobox gene HOXA10, a molecule wellknown to be involved in the mechanism of implantation, in human endometrial stromal cells (75) so that vitamin D might partly take on the role of progesterone in case of defective endometrial response mechanisms to this hormone. In addition, high doses of the anti-oxidant coenzyme Q10, previously shown to improve NK cell activity in patients with diabetes mellitus (76), may also be of help.

As to the lack of the attenuating effect of progesterone on uterine contractions provoked by embryo transfer, one solution might be postponing embryo transfer to day 5 of embryo development (7 days after ovulation trigger). It was reported that uterine contractility decreases progressively and reaches a nearly quiescent status 7 days after HCG administration, at the time of blastocyst transfers (77).

Recently, growth hormone has been shown to improve uterine receptivity in women with unexplained repeated implantation failure (78), including those in oocyte donation attempts with young oocyte donors, normal sperm characteristics, and fresh embryo transfer (79). The mechanism of this action is not known. However, growth hormone and progesterone share some components of their signaling pathways $(46,80,81)$, so that the deficiency of one might be compensated by the other. Anyway, all this remains a pure, though stimulating, speculation unless future studies generate definitive answers to these issues.

\section{REFERENCES}

1. Stocco C, Telleira C, Gibori G. The molecular control of corpus luteum formation, function, and regression. Endocr Rev. (2007) 28:11749. doi: 10.1210/er.2006-0022

2. Devoto L, Fuentes A, Kohen P, Céspedes P, Palomino A, Pommer R, et al. The human corpus luteum: life cycle and function in natural cycles. Fertil Steril. (2009) 92:1067-79. doi: 10.1016/j.fertnstert.2008.07.1745

3. Lenton EA, Landgren BM, Sexton L. Normal variation in the length of the luteal phase of the menstrual cycle: identification of the short luteal phase. $\mathrm{Br}$ J Obstet Gynaecol. (1984) 91:685-9. doi: 10.1111/j.1471-0528.1984.tb04831.x

\section{CONCLUSIONS}

LPD can occur in natural ovulatory cycles, causing infertility, though the prevalence of this condition remains to be determined. In ART attempts, LPD is quite a frequent complication. It was speculated that LPD in ART cycles is caused by an overreaction of $\mathrm{GnRH}$ analogs (agonists or antagonists) used to prevent premature ovulation during ovarian stimulation and/or by the inhibitory action of the ovulation trigger (HCG or $\mathrm{GnRH}$ agonist) on the forthcoming $\mathrm{LH}$ secretion by the pituitary, responsible for the maintenance of the CL activity required for endometrial receptivity until its role is taken over by embryo-derived HCG. In addition to these causes of LPD, marked by a low midluteal serum progesterone concentration, other cases of LPD can be caused by a defective response of target cells (endometrial epithelial and stromal cells, and uterine $\mathrm{T}$ lymphocytes) to normal concentrations of progesterone. LPD can cause implantation failure and miscarriage through inappropriate endometrial preparation for implantation, embryo expulsion through uterine contractions after embryo transfer, or immune rejection due to a failure of progesterone-induced reprogramming of uterine $\mathrm{T}$ cells and NK cells. LPD caused by insufficient progesterone secretion by the CL can be easily corrected, either by hormonal stimulation of the CL or by a direct supplementation of exogenous progesterone. On the other hand, LPD caused by a defective response of target cells to normal progesterone stimulus is more difficult to diagnose. If suspected, its consequences have to be treated with the use of symptomatic therapeutic protocols.

The strength of this study is its broad coverage of the subject. The weakness is that many new data are still largely hypothetical and need further confirmation.

\section{AUTHOR CONTRIBUTIONS}

The concept of this review was designed by JT, MG-L, CC-L, and RM-T. The initial manuscript draft was undertaken by JT. CC-L, MG-L, and RM-T contributed substantially to manuscript revision. The figures were designed by JT, CC-L, and RM-T. All artwork was produced by CC-L.

\section{ACKNOWLEDGMENTS}

The authors acknowledge technical assistance by the secretaries of MARGen Clinic, Granada.

4. Mesen TB, Young SL. Progesterone and the luteal phase: a requisite to reproduction. Obstet Gynecol Clin North Am. (2015) 42:135-51. doi: 10.1016/j.ogc.2014.10.003

5. Hodgen GD, Itskovitz J. Recognition and maintenance of pregnancy. In: Knobil E, Neill JD, editors. The Physiology of Reproduction, Vol. 2. 1st Edn. New York, NY: Raven Press (1988). p. 1995-2021.

6. Baird DD, Weinberg CR, McConnaughey DR, Wilcox AJ. Rescue of the corpus luteum in human pregnancy. Biol Reprod. (2003) 68:44856. doi: 10.1095/biolreprod.102.008425

7. Schliep KC, Mumford SL, Hammoud AO, Stanford JB, Kissell KA, Sjaarda LA, et al. Luteal phase deficiency in regularly menstruating 
women: prevalence and overlap in identification based on clinical and biochemical diagnostic criteria. J Clin Endocrinol Metab. (2014) 99:e100714. doi: 10.1210/jc.2013-3534

8. Jones HW Jr. Luteal-phase defect: the role of georgeanna seegar jones. Fertil Steril. (2008) 90:e5-7. doi: 10.1016/j.fertnstert.2007.08.036

9. Tesarik J, Mendoza N, Mendoza-Tesarik R. The neglected luteal phase after natural conception: rescue by early progesterone supplementation. Curr Opin Gyn Obstet. (2019) 2:216-20. doi: 10.18314/cogo.v2i1.1722

10. Casper RF. Luteal phase support for assisted reproduction. In: Tesarik J, editor. 40 Years After In Vitro Fertilisation: State of the Art and New Challenges. Cambridge: Cambridge Scholars Publishing (2019). p. 139-151.

11. Pritts EA, Atwood AK. Luteal phase support in infertility treatment: a meta-analysis of the randomized trials. Hum Reprod. (2002) 17:228799. doi: 10.1093/humrep/17.9.2287

12. Retamales I, Carrasco I, Troncoso JL, Las Heras J, Devoto L, Vega M. Morphofunctional study of human luteal cell subpopulations. Hum Reprod. (1994) 9:591-6. doi: 10.1093/oxfordjournals.humrep.a138555

13. Stouffer RL. Progesterone as a mediator of gonadotrophin action in the corpus luteum: beyond steroidogenesis. Hum Reprod Update. (2003) 9:99117. doi: 10.1093/humupd/dmg016

14. Marsh C, Schumacher K, Nothnick WB, Taylor RN, Monard M. Secterory phase and implantation. In: Menstrual Cycle. Chapter 4. IntechOpen (2018).

15. Gellersen B, Brosens JJ. Cyclic decidualization of the human endometrium in reproductive health and failure. Endocr Rev. (2014) 35:851-905. doi: 10.1210/er.2014-1045

16. Fox C, Morin S, Jeong JW, Scott RT Jr, Lessey BA. Local and systemic factors and implantation: what is the evidence? Fertil Steril. (2016) 105:87384. doi: 10.1016/j.fertnstert.2016.02.018

17. Jones GES. Some newer aspects of the management of infertility. J Am Med Assoc. (1949) 141:1123-9. doi: 10.1001/jama.1949.02910160013004

18. Edwards RG, Steptoe PC, Purdy JM. Establishing full-term human pregnancies using cleaving embryos grown in vitro. Br J Obstet Gynaecol. (1980) 87:737-56. doi: 10.1111/j.1471-0528.1980.tb04610.x

19. Garcia J, Jones GS, Acosta AA, Wright GL Jr. Corpus luteum function after follicle aspiration for oocyte retrieval. Fertil Steril. (1981) 36:56572. doi: 10.1016/S0015-0282(16)45852-8

20. Casper RF, Wilson E, Collins JA, Brown SF, Parker JA. Enhancement of human implantation by exogenous chorionic gonadotropin. Lancet. (1983) 2:1191. doi: 10.1016/S0140-6736(83)91233-3

21. Tavaniotou A, Albano C, Smitz J, Devroey P. Impact of ovarian stimulation on corpus luteum function and embryonic implantation. J Reprod Immunol. (2002) 55:123-30. doi: 10.1016/S0165-0378(01)00134-6

22. Fauser BC, Devroey P. Reproductive biology and IVF: ovarian stimulation and luteal phase consequences. Trends Endocrinol Metab. (2003) 14:23642. doi: 10.1016/S1043-2760(03)00075-4

23. Beckers NG, Macklon NS, Eijkemans MJ, Ludwig M, Felberbaum RE, Diedrich, et al. Nonsupplemented luteal phase characteristics after the administration of recombinant human chorionic gonadotropin, recombinant luteinizing hormone, or gonadotropin-releasing hormone $(\mathrm{GnRH})$ agonist to induce final oocyte maturation in in vitro fertilization patients after ovarian stimulation with recombinant follicle-stimulating hormone and GnRH antagonist cotreatment. J Clin Endocrinol Metab. (2003) 88:418692. doi: $10.1210 /$ jc.2002-021953

24. Fatemi HM. The luteal phase after 3 decades of IVF: what do we know? Reprod Biomed Online. (2009) 19 (Suppl. 4):113. doi: 10.1016/S1472-6483(10)61065-6

25. Miyake A, Aono T, Kinugasa T, Tanizawa O, Kurachi K. Suppression of serum levels of luteinizing hormone by short- and long-loop negative feedback in ovariectomized women. J Endocrinol. (1979) 80:353-6. doi: 10.1677/joe.0.0800353

26. Smitz J, Erard P, Camus M, Devroey P, Tournaye H, Wisanto A, et al. Pituitary gonadotrophin secretory capacity during the luteal phase in superovulation using GnRH-agonists and HMG in a desensitization or flare-up protocol. Hum Reprod. (1992) 7:1225-9. doi: 10.1093/oxfordjournals.humrep.a137831

27. Gonen Y, Balakier H, Powell W, Casper RF. Use of gonadotropin-releasing hormone agonist to trigger follicular maturation for in vitro fertilization. J Clin Endocrinol Metab. (1990) 71:918-22. doi: 10.1210/jcem-71-4-918
28. Segal S, Casper RF. Gonadotropin-releasing hormone agonist versus human chorionic gonadotropin for triggering follicular maturation in in vitro fertilization. Fertil Steril. (1992) 57:12548. doi: 10.1016/S0015-0282(16)55083-3

29. Benadiva C, Engmann L. Luteal phase support after gonadotropin-releasing hormone agonist triggering: does it still matter? Fertil Steril. (2018) 109:7637. doi: 10.1016/j.fertnstert.2018.02.003

30. Bar-Hava I, Mizrachi Y, Karfunkel-Doron D, Omer Y, Sheena L, Carmon $\mathrm{N}$, et al. Intranasal gonadotropin-releasing hormone agonist (GnRHa) for luteal-phase support following GnRHa triggering, a novel approach to avoid ovarian hyperstimulation syndrome in high responders. Fertil Steril. (2016) 106:330-3. doi: 10.1016/j.fertnstert.2016.04.004

31. Abdelhakim AM, Abd-ElGawad M, Hussein RS, Abbas AM. Vaginal versus intramuscular progesterone for luteal phase support in assisted reproductive techniques: a systematic review and metaanalysis of randomized controlled trials. Gynecol Endocrinol. (2020) 36:389-97. doi: 10.1080/09513590.2020.1727879

32. Abbara A, Clarke SA, Dhillo WS. Novel concepts for inducing final oocyte maturation in in vitro fertilization treatment. Endocr Rev. (2018) 39:59328. doi: 10.1210/er.2017-00236

33. Emperaire JC, Parneix I, Ruffie A. Luteal phase defects following agonisttriggered ovulation: a patient-dependent response. Reprod Biomed Online. (2004) 9:22-27. doi: 10.1016/S1472-6483(10)62105-0

34. Burney RO, Talbi S, Hamilton AE, Vo KC, Nyegaard M, Nezhat CR, et al. Gene expression analysis of endometrium reveals progesterone resistance and candidate susceptibility genes in women with endometriosis. Endocrinology. (2007) 148:3814-26. doi: 10.1210/en.2006-1692

35. Savaris RF, Groll JM, Young SL, DeMayo FJ, Jeong JW, Hamilton AE, et al. Progesterone resistance in PCOS endometrium: a microarray analysis in clomiphene citrate-treated and artificial menstrual cycles. J Clin Endocrinol Metab. (2011) 96:1737-46. doi: 10.1210/jc.2010-2600

36. Patel BG, Rudnicki M, Yu J, Shu Y, Taylor RN. Progesterone resistance in endometriosis: origins, consequences and interventions. Acta Obstet Gynecol Scand. (2017) 96:623-32. doi: 10.1111/aogs.13156

37. Hu M, Li J, Zhang Y, Li X, Brännström M, Shao LR, et al. Endometrial progesterone receptor isoforms in women with polycystic ovary syndrome. Am J Transl Res. (2018) 10:2696-705.

38. Tesarik J. Customised oocyte donation enhancement and new findings regarding the role of growth hormone. Eur Med J. (2018) 3:87-94.

39. Large MJ, DeMayo FJ. The regulation of embryo implantation and endometrial decidualization by progesterone receptor signaling. Mol Cell Endocrinol. (2012) 358:155-65. doi: 10.1016/j.mce.2011.07.027

40. Singh M, Chaudhry P, Asselin E. Bridging endometrial receptivity and implantation: network of hormones, cytokines, and growth factors. $J$ Endocrinol. (2011) 210:5-14. doi: 10.1530/JOE-10-0461

41. Lessey BA, Killam AP, Metzger DA, Haney AF, Greene GL, McCarty KS Jr. Immunohistochemical analysis of human uterine estrogen and progesterone receptors throughout the menstrual cycle. J Clin Endocrinol Metab. (1988) 67:334-40. doi: 10.1210/jcem-67-2-334

42. Ordi J, Creus M, Casamitjana R, Cardesa A, Vanrell JA, Balasch J. Endometrial pinopode and $\alpha v \beta 3$ integrin expression is not impaired in infertile patients with endometriosis. J Assist Reprod Genet. (2003) 20:46573. doi: 10.1023/B:JARG.0000006709.61216.6f

43. Matson BC, Pierce SL, Espenschied ST, Holle E, Sweatt IH, Davis ES, et al. Adrenomedullin improves fertility and promotes pinopodes and cell junctions in the peri-implantation endometrium. Biol Reprod. (2017) 97:46677. doi: 10.1093/biolre/iox101

44. Kabir-Salmani M, Nikzad H, Shiokawa S, Akimoto Y, Iwashita M. Secretory role for human uterodomes (pinopods): secretion of LIF. Mol Hum Reprod. (2005) 11:553-9. doi: 10.1093/molehr/gah218

45. Qian ZD, Weng Y, Wang CF, Huang LL, Zhu XM. Research on the expression of integrin $\beta 3$ and leukaemia inhibitory factor in the decidua of women with cesarean scar pregnancy. BMC Pregnancy Childbirth. (2017) 17:84. doi: 10.1186/s12884-017-1270-3

46. Massimiani M, Lacconi V, La Civita F, Ticconi C, Rago R, Campagnolo L. Molecular signaling regulating endometrium-blastocyst crosstalk. Int J Mol Sci. (2020) 21:23. doi: 10.3390/ijms21010023 
47. Wetendorf M, DeMayo FJ. The progesterone receptor regulates implantation, decidualization, and glandular development via a complex paracrine signaling network. Mol Cell Endocrinol. (2012) 357:108-18. doi: 10.1016/j.mce.2011.10.028

48. Fanchin R, Righini C, de Ziegler D, Olivennes F, Ledée N, Frydman R. Effects of vaginal progesterone administration on uterine contractility at the time of embryo transfer. Fertil Steril. (2001) 75:1136-40. doi: 10.1016/S0015-0282(01)01787-3

49. Szekeres-Bartho J. The role of progesterone in feto-maternal immunological cross talk. Med Princ Pract. (2018) 27:301-7. doi: 10.1159/000491576

50. Lim MK, Ku CW, Tan TC, Justin Lee YH, Allen JC, Tan NS. Characterisation of serum progesterone and progesterone-induced blocking factor (PIBF) levels across trimesters in healthy pregnant women. Sci Rep. (2020) 10:3840. doi: 10.1038/s41598-020-59452-y

51. Campbell D, Koch M. Phenotypical and functional specialization of FOXP3 $^{+}$regulatory $\mathrm{T}$ cells. Nat Rev Immunol. (2011) 11:119-30. doi: 10.1038/nri2916

52. Koopman LA, Kopcow HD, Rybalov B, Boyson JE, Orange JS, Schatz F, et al. Human decidual natural killer cells are a unique NK cell subset with immunomodulatory potential. J Exp Med. (2003) 198:120112. doi: 10.1084 /jem. 20030305

53. Feyaerts D, Kuret T, van Crankenbroek B, van der Zeeuw-Hingrez S, van der Heijden OWH, van der Meer A, et al. Endometrial natural killer (NK) cells reveal a tissue-specific receptor repertoire. Hum Reprod. (2018) 33:44151. doi: 10.1093/humrep/dey001

54. Fu B, Li X, Sun R, Tong X, Ling B, Tian Z, et al. Natural killer cells promote immune tolerance by regulating inflammatory TH17 cells at the human maternal-fetal interface. Proc Natl Acad Sci USA. (2013) 110:E23140. doi: 10.1073/pnas.1206322110

55. Tesarik J, Hazout A, Mendoza-Tesarik R, Mendoza N, Mendoza C. Beneficial effect of luteal-phase GnRH agonist administration on embryo implantation after ICSI in both GnRH agonist- and antagonist-treated ovarian stimulation cycles. Hum Reprod. (2006) 21:2572-9. doi: 10.1093/humrep/del173

56. Filicori M, Butler JP, Crowley WF Jr. Neuroendocrine regulation of the corpus luteum in the human. Evidence for pulsatile progesterone secretion. J Clin Invest. (1984) 73:1638-47. doi: 10.1172/JCI111370

57. Hansen KR, Eisenberg E, Baker V, Hill MJ, Chen S, Talken S, et al. Midluteal progesterone: a marker of treatment outcomes in couples with unexplained infertility. J Clin Endocrinol Metab. (2018) 103:274351. doi: 10.1210/jc.2018-00642

58. Díaz-Gimeno P, Horcajadas JA, Martínez-Conejero JA, Esteban FJ, Alamá P, Pellicer A, et al. A genomic diagnostic tool for human endometrial receptivity based on the transcriptomic signature. Fertil Steril. (2011) 95:5060.e615. doi: 10.1016/j.fertnstert.2010.04.063

59. Ruiz-Alonso M, Blesa D, Díaz-Gimeno $\mathrm{P}$, Gómez E, FernándezSánchez M, Carranza $F$, et al. The endometrial receptivity array for diagnosis and personalized embryo transfer as a treatment for patients with repeated implantation failure. Fertil Steril. (2013) 100:818-24. doi: 10.1016/j.fertnstert.2013.05.004

60. Bassil R, Casper R, Samara N, Hsieh T-B, Barzilay E, Orvieto R, et al. Does the endometrial receptivity array really provide personalized embryo transfer? J Assist Reprod Genet. (2018) 35:1301-5. doi: 10.1007/s10815-018-1190-9

61. Enciso M, Carrascosa JP, Sarasa J, Martinez-Ortiz PA, Munné S, Horcajadas JA, et al. Development of a new comprehensive and reliable endometrial receptivity map (ER Map/ER grade) based on RT-qPCR gene expression analysis. Hum Reprod. (2018) 33:220-8. doi: 10.1093/humrep/dex370

62. van der Linden M, Buckingham K, Farquhar C, Kremer JA, Metwally M. Luteal phase support for assisted reproduction cycles. Cochrane Database Syst Rev. (2011) 10:CD009154. doi: 10.1002/14651858.CD009154

63. Griesinger G, Blockeel C, Sukhikh GT, Patki A, Dhorepatil B, Yang DZ, et al. Oral dydrogesterone versus intravaginal micronized progesterone gel for luteal phase support in IVF: a randomized clinical trial. Hum Reprod. (2018) 33:2212-21. doi: 10.1093/humrep/dey306

64. Neumann K, Depenbusch M, Schultze-Mosgau A, Griesinger G. Characterization of early pregnancy placental progesterone production by use of dydrogesterone in programmed frozen-thawed embryo transfer cycles. Reprod Biomed Online. (2020) 40:743-51. doi: 10.1016/j.rbmo.2020.01.019
65. Tesarik J. Can miscarriage caused by delayed luteoplacental shift be avoided? Reprod Biomed Online. (2020) 41:747. doi: 10.1016/j.rbmo.2020.07.010

66. Pirard C, Loumaye E, Laurent P, Wyns C. Contribution to more patientfriendly ART treatment: efficacy of continuous low-dose GnRH agonist as the only luteal support-results of a prospective, randomized, comparative study. Int J Endocrinol. (2015) 2015:727569. doi: 10.1155/2015/727569

67. Mendoza-Tesarik R, Mendoza N, López CC, Tesarik J. GnRH agonist treatment of luteal phase deficiency in HCG-triggered IVF cycles: a matched case-control study. Reprod Biomed Online. (2019) 39:22530. doi: 10.1016/j.rbmo.2019.03.215

68. Tesarik J, Hazout A, Mendoza C. Enhancement of embryo developmental potential by a single administration of GnRH agonist at the time of implantation. Hum Reprod. (2004) 19:1176-80. doi: 10.1093/humrep/deh235

69. Liang Y, Liu L, Jin Z, Liang XH, Fu YS, Gu XW, et al. The high concentration of progesterone is harmful for endometrial receptivity and decidualization. Sci Rep. (2018) 8:712. doi: 10.1038/s41598-017-18643-w

70. Tarocco A, Caroccia N, Morciano G, Wieckowski MR, Ancora G, Garani $\mathrm{G}$, et al. Melatonin as a master regulator of cell death and inflammation: molecular mechanisms and clinical implications for newborn care. Cell Death Dis. (2019) 10:317. doi: 10.1038/s41419-019-1556-7

71. Chuffa LGA, Lupi LA, Cucielo MS, Silveira HS, Reiter RJ, Seiva FRF. Melatonin promotes uterine and placental health: potential molecular mechanisms. Int J Mol Sci. (2019) 21:300. doi: 10.3390/ijms21010300

72. Jerzak M, Kniotek M, Mrozek J, Górski A, Baranowski W. Sildenafil citrate decreased natural killer cell activity and enhanced chance of successful pregnancy in women with a history of recurrent miscarriage. Fertil Steril. (2008) 90:1848-53. doi: 10.1016/j.fertnstert.2007.08.043

73. Kniotek M, Boguska A. Sildenafil can affect innate and adaptive immune system in both experimental animals and patients. J Immunol Res. (2017) 2017:4541958. doi: 10.1155/2017/4541958

74. Cermisoni GC, Alteri A, Corti L, Rabellotti E, Papaleo E, Viganò P, et al. Vitamin D and endometrium: a systematic review of a neglected area of research. Int J Mol Sci. (2018) 19:2320. doi: 10.3390/ijms19082320

75. Du H, Daftary GS, Lalwani SI, Taylor HS. Direct regulation of HOXA10 by $1,25-(\mathrm{OH}) 2 \mathrm{D} 3$ in human myelomonocytic cells and human endometrial stromal cells. Mol Endocrinol. (2005) 19:2222-33. doi: 10.1210/me.2004-0336

76. Brauner H, Lüthje P, Grünler J, Ekberg NR, Dallner G, Brismar K, et al. Markers of innate immune activity in patients with type 1 and type 2 diabetes mellitus and the effect of the anti-oxidant coenzyme Q10 on inflammatory activity. Clin Exp Immunol. (2014) 177:478-82. doi: 10.1111/cei.12316

77. Fanchin R, Ayoubi JM, Righini C, Olivennes F, Schönauer LM, Frydman R. Uterine contractility decreases at the time of blastocyst transfers. Hum Reprod. (2001) 16:1115-19. doi: 10.1093/humrep/16.6.1115

78. Xu YM, Hao GM, Gao BL. Application of growth hormone in in vitro fertilization. Front Endocrinol. (2019) 10:502. doi: 10.3389/fendo.2019.00502

79. Altmäe S, Mendoza-Tesarik R, Mendoza C, Mendoza N, Cucinelli F, Tesarik J. Effect of growth hormone on uterine receptivity in women with repeated implantation failure in an oocyte donation program: a randomized controlled trial. J Endocr Soc. (2017) 2:96-105. doi: 10.1210/js.2017-00359

80. Altmäe S, Aghajanova L. Growth hormone and endometrial receptivity. Front Endocrinol. (2019) 10:653. doi: 10.3389/fendo.2019.0 0653

81. Fatemi HM. Simplifying luteal phase support in stimulated assisted reproduction cycles. Fertil Steril. (2018) 110:10356. doi: 10.1016/j.fertnstert.2018.08.019

Conflict of Interest: The authors declare that the research was conducted in the absence of any commercial or financial relationships that could be construed as a potential conflict of interest.

Copyright (c) 2020 Tesarik, Conde-López, Galán-Lázaro and Mendoza-Tesarik. This is an open-access article distributed under the terms of the Creative Commons Attribution License (CC BY). The use, distribution or reproduction in other forums is permitted, provided the original author(s) and the copyright owner(s) are credited and that the original publication in this journal is cited, in accordance with accepted academic practice. No use, distribution or reproduction is permitted which does not comply with these terms. 